\title{
Effect of Metformin on FSH, LH and Prolactin Levels in Patients with Polycystic Ovarian Syndrome
}

\author{
Purnima Jindal ${ }^{1}$, Rachna Mehandiratta $^{2}$, Anuj Sharma ${ }^{3}$, Vikrom Takkar $^{4}$, Preeti Takkar Kapila \\ 1Assistant Professor, Department of Biochemistry, Glocal Medical College Superspeciality Hospital \& \\ Research Centre, Mirzapurpole, Saharanpur (U.P.) and Postgraduate from GMC, Patiala, Punjab, India. \\ ${ }^{2}$ Associate Professor, Department of Biochemistry, ${ }^{3}$ Associate Professor, Department of Pathology, \\ Maharishi Markandeshwar Medical College and Hospital, Kumarhatti, Solan, Himachal Pradesh, India. \\ ${ }^{4}$ Medical Officer, Department of Anaesthesia, District Hospital, Solan, Himachal Pradesh, India. \\ ${ }^{5}$ Resident (IIIrd yr.), Department of Radiology, Dr. Rajendra Prasad Govt. Medical College, \\ Tanda, Kangra, Himachal Pradesh, India.
}

\begin{abstract}
Objective: Polycystic ovarian syndrome (PCOS) is a common endocrine disorder affecting young females. They present with irregular menses, infertility, obesity, hirsutism, acanthosis nigricans, etc. Women with polycystic ovary syndrome (PCOS) exhibit insulin resistance. Insulin sensitizers, especially metformin, have been shown to improve the hormonal \& biochemical profile, but there are only a few studies on their effects on serum FSH (Follicle stimulating hormone), LH (Luteinizing Hormone), and Prolactin in PCOS. The aim of the present study was to elucidate the dynamics of $\mathrm{FSH}, \mathrm{LH}$, and Prolactin and the effect of metformin therapy on their levels in patients of PCOS.

Methods: In this study, 60 women aged $16-40$ years with PCOS were selected. Diagnostic criteria were based on the diagnostic criteria of PCO syndrome in Rotterdam ESHRE (European Society for Human Reproduction) / ASRM (American Society of Reproductive Medicine) Sponsored PCOS Consensus Workshop Group (2004). Samples of peripheral blood were taken from all patients. Serum levels of $\mathrm{FSH}, \mathrm{LH}$ and prolactin along with routine investigations were estimated at the start of treatment and were repeated after 6 months of metformin treatment in a dosage of $1500 \mathrm{mg}$ in divided doses. Also, BMI was compared before and after treatment.
\end{abstract}

Results: The mean BMI before treatment was $24.6 \pm 2.9$ $\mathrm{kg} / \mathrm{m}^{2}$ and after treatment was $23.8 \pm 2.8 \mathrm{~kg} / \mathrm{m}^{2}(\mathrm{p}<0.0001)$. The mean FSH levels before and after treatment were $10.55 \pm 6.22$

\section{INTRODUCTION}

Polycystic ovarian syndrome originally described in 1905 by Stein and Leventhal, is the commonest endocrine disorder in women of reproductive age leading to menstrual irregularity; which is one of the cardinal clinical features of PCOS ${ }^{1}$. 6-10\% of women population is affected globally. ${ }^{2}$ The signs of PCOS include hyperandrogenism and anovulation. Since the cause of this syndrome has not been diagnosed yet, therefore its treatment will be depending on signs and patients characteristics such as: hirsutism, obesity, menstrual disorder and infertility ${ }^{3}$.
$\mathrm{mlU} / \mathrm{ml}$ and $9.69 \pm 4.07 \mathrm{mlU} / \mathrm{ml}$ respectively $(p<0.1374)$. Mean LH levels before and after treatment were $22.34 \pm 11.49$ $\mathrm{mlU} / \mathrm{ml}$ and $15.65 \pm 6.09 \mathrm{mlU} / \mathrm{ml}$ respectively $(p<0.0001)$. The mean $\mathrm{LH} / \mathrm{FSH}$ ratio before and after treatment was $2.55 \pm$ 1.35 and $1.79 \pm 0.79$ respectively $(p<0.0001)$. Mean prolactin level before treatment was $20.99 \pm 8.37 \mathrm{ng} / \mathrm{ml}$ and after treatment was $18.05 \pm 5.22 \mathrm{ng} / \mathrm{ml}(p<0.0001)$.

Conclusion: In women with PCOS, metformin treatment had beneficial effects on hormonal profile and therefore it could be useful in the correction of menstrual irregularity, anovulation and infertility in these women.

Key Words: Metformin, PCO syndrome, FSH, LH.

\section{*Correspondence to}

Dr. Rachna Mehandiratta,

Vikrom Niwas,

Jawahar Park Road,

Solan, HP, India

\section{Article History:}

Received: 03-09-2016, Revised: 14-09-2016, Accepted: 28-09-2016

\begin{tabular}{|l|r|}
\hline \multicolumn{2}{|c|}{ Access this article online } \\
\hline $\begin{array}{l}\text { Website: } \\
\text { www.ijmrp.com }\end{array}$ & Quick Response code \\
\hline DOI: & \\
10.21276/ijmrp.2016.2.5.037 & \\
\hline
\end{tabular}


The effects of insulin-activity sensitizer metformin on PCOS related biological, biochemical, hormonal and metabolic manifestations have been extensively investigated and reviewed. However, certain aspects related to the mechanism of metformin's actions remain still uncertain. In particular, little attention has been paid to the possible role played by the hypothalamic-pituitary complex as a recipient of metformin's direct action, as an indirect consequence of its effects in the ovary or both mechanisms. ${ }^{6}$

Keeping this in mind, the aim of our study was to investigate the effect of metformin on hormonal profile in women with PCOS.

\section{MATERIALS AND METHODS}

The present study was conducted in the Department of Biochemistry in collaboration with Department of Obstetrics and Gynaecology, Govt. Medical College, Patiala. The study was approved by the institutional ethical committee.

A total of 60 female patients( in the range of $16-40$ years) reporting to the outpatient department of Obstetrics and Gynaecology, Rajindra Hospital, Patiala with clinical features suggestive of PCOS were included in the study.

The presence of any two of the following criteria was used to diagnose PCOS as laid down by the Rotterdam ESHRE/ ASRM Sponsored PCOS Consensus Workshop Group (2004):

1. Oligo-ovulation or anovulation

2. Clinical and/ or biochemical hyperandrogenism

3. Polycystic ovaries

And exclusive of congenital adrenal hyperplasia, androgen secreting tumours and Cushing's syndrome.

\section{Selection Criteria}

1. Oligomenorrhoea (<6 cycles/ year), secondary amenorrhoea or hypomenorrhoea (bleeding $<1$ day) with obesity.

2. Oligomenorrhoea (<6 cycles/ year), secondary amenorrhoea or hypomenorrhoea (bleeding $<1$ day) with hirsutism.

3. Oligomenorrhoea ( $<6$ cycles/ year), secondary amenorrhoea or hypomenorrhoea (bleeding $<1$ day) with acne.

4. Oligomenorrhoea (<6 cycles/ year), secondary amenorrhoea or hypomenorrhoea (bleeding $<1$ day) with infertility.

The menstrual cycle was described as being oligomenorrhoeic (a cycle interval of longer than 35 days but less than six months), amenorrhoeic (no menstruation for more than six months) or hypomenorrhoeic (bleeding lasting less than 1 day).

\section{Exclusion criteria}

1. Infertility due to male factors

2. Infertility due to tubal factors

3. Infertility due to cervical factors

4. Hyperprolactinemia

5. Thyroid disorders

6. Adrenal hyperplasia

7. Cushing's syndrome

8. Androgen producing tumors

The fertility status was classified as "proven fertile" (those with a previous pregnancy and non-subsequent infertility), "fertility untested" (those who had never tried to conceive) or "infertile".

\section{Methodology}

The patients fulfilling the above criteria were included in the study. A detailed history was recorded with particular reference to menstrual irregularity, obesity, hirsutism, acne and infertility. Informed consent was taken from every patient before including her in the study. It was a 6 months prospective randomized study involving 60 patients of PCOS. Serum FSH, LH, Prolactin and $\mathrm{LH} / \mathrm{FSH}$ ratio were estimated at the start of treatment and were repeated after 6 months of metformin treatment in a dosage of $1500 \mathrm{mg}$ in divided doses.

Height and weight measurements were done to calculate the BMI. Evidence of hirsutism, acne was looked for.

\section{ASSAYS}

\section{Hormonal Profile}

$5 \mathrm{ml}$ blood was taken under aseptic precautions from the patient and serum was separated for estimation of FSH, LH and prolactin using Enzyme Linked Immunosorbent Assay (ELISA). Sample collection was done on $3^{\text {rd }}$ day of menstrual cycle and in amenorrhoeic patients sample was taken after withdrawal bleeding.

SSPS version 13 was used to do the appropriate statistical tests including Student's T Test (two- tailed), Fisher exact test. The results were expressed as means and standard deviation. Differences were considered to be statistically significant if $p$-value was $<0.05$.

\section{RESULTS}

In the present study, 60 patients with clinical features suggestive of PCOS who attended the outpatient department of Obstetrics and Gynaecology Department of Rajindra Hospital attached to Govt. Medical College, Patiala were evaluated. Serum levels of FSH, LH, Prolactin and LH/FSH ratio were estimated and were repeated after 6 months of treatment with metformin. The study was done over a period of 12 months and the following observations were made.

The mean age of patients was $22.8 \pm 4.65$ years with a range of 16 years to 38 years. The maximum number of patients (25) was in the $21-25$ years age group. (Table 1)

Menstrual irregularity was seen in $90 \%$ of the patients (Oligomenorrhea or secondary amenorrhoea). Infertility was present in $25 \%$ patients while $71.67 \%$ of the patients presented with features of hyperandrogenism. $26.67 \%$ patients were overweight and $8.33 \%$ patients were obese. $83.33 \%$ patients had polycystic ovaries on ultrasonography. Discrepancy in total number of patients was due to overlapping of symptoms. (Table 2) The mean BMl levels before giving treatment were $24.62 \pm 2.91$ $\mathrm{kg} / \mathrm{m}^{2}$ and significantly decreased to $23.80 \pm 2.85 \mathrm{~kg} / \mathrm{m}^{2}$ after giving treatment $(p<0.0001)$. (Table 3 )

The mean FSH level before giving treatment was $10.55 \pm 6.22$ $\mathrm{mlU} / \mathrm{ml}$ and after giving treatment was $9.69 \pm 4.07 \mathrm{mlU} / \mathrm{ml}$. Statistical analysis showed that difference in the mean values of FSH was not significant $(p<0.1374)$. (Table 4)

The mean LH level before giving treatment was $22.34 \pm 11.49$ $\mathrm{mlU} / \mathrm{ml}$ and after giving treatment was $15.65 \pm 6.09 \mathrm{mlU} / \mathrm{ml}$. Statistical analysis showed that difference in the mean values of LH was highly significant $(p<0.0001)$ (Table 4)

The mean LH/FSH ratio before and after giving treatment was $2.55 \pm 1.35$ and $1.79 \pm 0.79$ respectively. The difference in the mean values of LH/FSH ratio was highly significant $(p<0.0001)$. (Table 4)

Mean prolactin levels before and after giving treatment were 20.99 $\pm 8.37 \mathrm{ng} / \mathrm{ml}$ and $18.05 \pm 5.22$ respectively. Statistical analysis showed this difference in the mean values of prolactin to be highly significant $(p<0.0001)$. (Table 4) 
Table 1: Distribution of patients according to age

\begin{tabular}{|c|c|c|}
\hline Age in years & No. of cases & \%age \\
\hline $16-20$ & 20 & 33.33 \\
\hline $21-25$ & 25 & 41.67 \\
\hline $26-30$ & 12 & 20 \\
\hline $31-35$ & 2 & 3.33 \\
\hline $36-40$ & 1 & 1.67 \\
\hline Total & 60 & 100 \\
\hline Range & \multicolumn{2}{|c|}{$16-38$} \\
\hline Mean \pm SD & \multicolumn{2}{|c|}{$22.8 \pm 4.65$} \\
\hline
\end{tabular}

Table 2: Showing distribution of patients according to clinical presentation

\begin{tabular}{lcc}
\hline Clinical Presentation & No. of patients & \%age \\
\hline Menstrual irregularity & 54 & 90 \\
Infertility & 15 & 25 \\
Clinical hyperandrogenism & 43 & 71.67 \\
Overweight & 16 & 26.67 \\
Obesity & 5 & 8.33 \\
Polycystic ovaries on ultrasonography & 50 & 83.33 \\
\hline
\end{tabular}

Note: Discrepancy in total number of patients due to overlapping of symptoms.

Table 3: Showing BMI changes after giving metformin for 6 months

\begin{tabular}{lccccc}
\hline & \multicolumn{3}{c}{ BMI $\left(\mathbf{k g} / \mathrm{m}^{2}\right)$} & & \\
\hline & Before & After & $\mathbf{t}$ & $\mathbf{p}$ & $\mathbf{S}$ \\
Range & $20.2-32.5$ & $17.6-31.6$ & 9.72 & $<0.0001$ & HS \\
Mean \pm SD & $24.62 \pm 2.91$ & $23.80 \pm 2.85$ & & & \\
\hline
\end{tabular}

Table 4: Showing change in FSH, LH, LH/FSH ratio and Prolactin levels after treatment with metformin for 6 months

\begin{tabular}{lccccc}
\hline Parameter & $\begin{array}{c}\text { Before } \\
\text { (Mean } \pm \text { SD) }\end{array}$ & $\begin{array}{c}\text { After } \\
\text { (Mean } \pm \text { SD) }\end{array}$ & $\mathbf{t}$ & $\mathbf{p}$ & $\mathbf{S}$ \\
\hline FSH (mlU/ml) & $10.55 \pm 6.22$ & $9.69 \pm 4.07$ & 1.50 & $<0.1374$ & NS \\
LH (mlU/ml) & $22.34 \pm 11.49$ & $15.65 \pm 6.09$ & 6.71 & $<0.0001$ & HS \\
LH/FSH ratio & $2.55 \pm 1.35$ & $1.79 \pm 0.79$ & 6.09 & $<0.0001$ & HS \\
Prolactin $(\mathrm{ng} / \mathrm{ml})$ & $20.99 \pm 8.37$ & $18.05 \pm 5.22$ & 4.23 & $<0.0001$ & HS \\
\hline
\end{tabular}

\section{DISCUSSION}

PCOS is an endocrine disorder seen in women of reproductive age. It describes a convergence of chronic multisystem endocrine derangements including menstrual irregularity, subfertility, obesity, hyperandrogenism, hyperlipidemia and large polycystic ovaries. Also it is a comprehensive syndrome with a variety of associated metabolic disorders which predispose these women to diabetes mellitus, coronary heart disease and myocardial infarction.

PCOS is often perimenarcheal in onset but it has not been extensively investigated in the adolescent population. In the present study, the mean age of the patients was $22.8 \pm 4.6$ years which was comparable to the study conducted by DiamantiKandarakis et al where the mean age was $24.6 \pm 1.8$ years. $^{7}$ Wijeyratne et al studied the clinical manifestations of PCOS among South Asians and concluded that South Asians presented at a younger age group as compared to Caucasians. ${ }^{8}$

Balen et al. suggested that there is a substantial heterogeneity of symptoms and signs among women with PCOS. ${ }^{9}$ Several interlinking factors affect the expression of PCOS and for an individual it may change over time. In our study also patients presented with varied clinical presentation including menstrual irregularities (oligomenorrhoea, secondary amenorrhoea), hirsutism, obesity and infertility. High levels of LH and androgens have been regarded as a cause of increased number of oligomenorrhoeic patients under study. In our study, mean values in BMI decreased significantly. Our results are comparable with the studies conducted by Gleuck et al. ${ }^{10}$ On the contrary; De Leo et al. reported non-significant change in BMI after treatment with metformin. ${ }^{11}$ Reduction in BMl could be explained due to normalization of plasma insulin by metformin resulting in reduced appetite which led to weight reduction in PCOS patients.

Our results demonstrated that metformin treatment improved the hormonal profile in PCOS i.e. there was significant decrease in serum levels of $\mathrm{LH}$, Prolactin along with significant decrease $\mathrm{LH} / \mathrm{FSH}$ ratio $(p<0.0001)$. There was a decrease in FSH levels also but not to a significant extent $(p<0.1374)$. Our results are in line with previous studies on PCOS, where metformin has been shown to improve the hormonal profile, mainly by decreasing serum FSH, LH, and prolactin. ${ }^{12}$

In the present study, serum LH levels decreased from $22.3 \pm 11.4$ $\mathrm{mIU} / \mathrm{ml}$ to $15.5 \pm 6.0 \mathrm{mlU} / \mathrm{ml}$ with $\mathrm{p}<0.0001$ which is highly significant. Nestler et al. also showed a similar result. ${ }^{2}$ However, 
Ehrmann et al. ${ }^{13}$ reported that $\mathrm{LH}$ levels remain unaffected after treatment with metformin whereas De Leo et al showed that the reduction in LH was non-significant. ${ }^{11}$ Metformin treatment reduces hyperinsulinemia. It is considered to be a cause of altered pituitary sensitivity to gonadotrophin releasing hormone which leads to over secretion of $\mathrm{LH}$. Metformin administration leads to reduction in $\mathrm{LH}$ response to $\mathrm{GnRH}$.

In the present study, no significant change was seen in FSH levels after 6 month of treatment. De Leo et al. ${ }^{11}$ and Vincenzo et al. showed slight increment in FSH levels which was nonsignificant. ${ }^{14}$ Our study was comparable to the study conducted by Ehrmann et al. who reported that FSH levels remain unaffected after treatment with metformin. ${ }^{13}$

Present study also showed reduction in mean values of LH/FSH ratio from $2.5 \pm 1.3$ to $1.7 \pm 0.7$ after 6 months of metformin treatment which was highly significant and comparable to the studies conducted by Vincenzo et al. ${ }^{14}$ and Velazquez who reported significant reduction in LH/FSH ratio. ${ }^{15}$ In the present study, LH has decreased significantly and there is no significant change in FSH. So LH / FSH ratio is also decreased significantly.

Present study showed significant reduction in mean value in prolactin after 6 month of treatment. Not many studies are found showing effect of metformin on prolactin levels. Kazerooni et al. showed that there is no effect of metformin on prolactin after 6 month of treatment. ${ }^{16}$ The discrepancy could be explained by difference in study populations or due to different duration of treatment in various studies.

\section{CONCLUSION}

Etiopathogenesis of PCOS is complex, multifactorial and poorly understood. The beneficial effect of metformin on the hormonal profile corroborates well with the existing data suggesting that metformin is an effective drug in reversing insulin-resistance and therefore in the management of anovulatory infertility and prevention of long-term consequences So, metformin appears to be a drug with multiple therapeutic effects far beyond its effect on lowering blood glucose in diabetes mellitus and should be integrated in the spectrum of therapeutic options of PCOS.

\section{REFERENCES}

1. Goudas VT, Dumesic DA. Polycystic ovary syndrome. Endocrinol Metab Clin North Am. 1997 Dec; 26(4):893-912.

2. Nestler JE, Jakubowicz DJ, Evans WS, Pasquali R. Effects of metformin on spontaneous and clomiphene-induced ovulation in the polycystic ovary syndrome. N Engl J Med. 1998; 338:1876-80. 3. Ajossa S, Guerriero S, Paoletti AM, Orru M, Melis GB. The treatment of polycystic ovary syndrome. Minerva Gynecol. 2004; 56:15-26.

4. Awalekar J, Awalekar C, Jadhav VM, Chivate CG, Patwardhan MH. Effect of Metformin in Patients of Polycystic Ovarian Disease (PCOD), a Comparative \& Observational Study. International Journal of Biomedical research. 2015; 6(9):698-704.

5. Taylor AE, McCourt B, Martin KA, Anderson EJ, Adams JM, Schoenfeld $D$ et al. Determinants of abnormal gonadotropin secretion in clinically defined women with polycystic ovary syndrome. J Clin Endocrinol Metab 1997; 82:2248-56.
6. Billa E, Kapolla N, Nicopoulou SC, Koukkou E, Venaki E, Milingos $S$ et al. Metformin administration was associated with a modification of $\mathrm{LH}$, prolactin and insulin secretion dynamics in women with polycystic ovarian syndrome. Gynecological Endocrinology. 2009; 25(7):427-34.

7. Diamanti-Kandarakis E, Kouli CR, Bergiele AT, Filandra FA, Tsianateli TC, Spina GG et al. A survey of the polycystic ovary syndrome in the Greek island of Lesbos: hormonal and metabolic profile. J Clin Endocrinol Metab. 1999; 84(11): 4006-11.

8. Wijeyaratne $\mathrm{CN}$, Balen AH, Barth $\mathrm{JH}$, Belchetz PE. Clinical manifestations and insulin resistance (IR) in polycystic ovary syndrome (PCOS) among South Asians and Caucasians: is there a difference? Clin Endocrinol. 2002; 57(3): 343-50.

9. Balen AH, Conway GS, Kaltsas G Techatrasak K, Manning PJ, West $C$ et al. Polycystic ovary syndrome: the spectrum of the disorder in 1741 patients. Hum Reprod 1995; 10(8): 2107-11.

10. Glueck CJ, Papanna R, Wang P, Goldenberg N, Sieve-Smith $\mathrm{L}$. Incidence and treatment of metabolic syndrome in newly referred women with confirmed polycystic ovary syndrome. Metabolism. 2003; 52(7): 908-15.

11. De Leo V, Marca AL, Orvieto R, Morgante G. Effect of Metformin on Insulin-Like Growth Factor (IGF) I and IGF-Binding Protein I in Polycystic Ovary Syndrome. J Clin Endocrinol Metab. 2000; 85(4): 1598-1600.

12. Baqer LS, Alobaidi AH, Ehmaed MS, Alsamarai AM. Evaluation of the effect of metformin on hormone serum levels in women with polycystic ovary syndrome. World Journal of Pharmacy and Pharmaceutical Sciences. 2015; 4(6), 1574-81.

13. Ehrman DA, Cavaghan MK, Imperial J, Sturis J, Rosenfield RI, Polonsky KS. Effects of metformin on insulin secretion, insulin action and ovarian steroidogenesis in women with polycystic ovary syndrome. J Clin Endocrinol Metab. 1997; 82:524.

14. Vincenzo DL, Musacchio MC, Morgante G, Piomboni $P$, Petraglia F. Metformin treatment is effective in obese teenage girls with PCOS. Human Reproduction. 2006; 21(9):2252-6.

15. Velazquez E, Acosta A, Mendoza SG. Menstrual cyclicity after metformin therapy in polycystic ovary syndrome. Obstetrics \& Gynecology. 1997: 90:392-5.

16. Kazerooni T, Dehghan-Kooshkghazi M. Effects of metformin therapy on hyperandrogenism in women with PCOS. Gynecological endocrinology. 2003; 17(1): 51-6.

\section{Source of Support: Nil. Conflict of Interest: None Declared.}

Copyright: (c) the author(s) and publisher. IJMRP is an official publication of Ibn Sina Academy of Medieval Medicine \& Sciences, registered in 2001 under Indian Trusts Act, 1882. This is an open access article distributed under the terms of the Creative Commons Attribution Non-commercial License, which permits unrestricted non-commercial use, distribution, and reproduction in any medium, provided the original work is properly cited.

Cite this article as: Purnima Jindal, Rachna Mehandiratta, Anuj Sharma, Vikrom Takkar, Preeti Takkar Kapila. Effect of Metformin on FSH, LH and Prolactin Levels in Patients with Polycystic Ovarian Syndrome. Int J Med Res Prof. 2016; 2(5):176-79. 